GA-A16027 MNTER

\title{
HTGR-GT PRIMARY COOLANT TRANSIENT RESULTING FROM POSTULATED TURBINE DEBLADING
}

by

G. J. CADWALLADER and R. K. DEREMER

NOVEMBER 1980

\section{GENERAL ATOMIC COMPANY}




\section{DISCLAIMER}

This report was prepared as an account of work sponsored by an agency of the United States Government. Neither the United States Government nor any agency Thereof, nor any of their employees, makes any warranty, express or implied, or assumes any legal liability or responsibility for the accuracy, completeness, or usefulness of any information, apparatus, product, or process disclosed, or represents that its use would not infringe privately owned rights. Reference herein to any specific commercial product, process, or service by trade name, trademark, manufacturer, or otherwise does not necessarily constitute or imply its endorsement, recommendation, or favoring by the United States Government or any agency thereof. The views and opinions of authors expressed herein do not necessarily state or reflect those of the United States Government or any agency thereof. 


\section{DISCLAIMER}

Portions of this document may be illegible in electronic image products. Images are produced from the best available original document. 


\section{DISCLAIMER}

This report was prepared as an account of work sponsored by an agency of the United States Government. Neither the United States Government nor any agency thereof, nor any of their employees, makes any warranty, express or implied, or assumes any legal liability or responsibility for the accuracy, completeness, or usefulness of any information, apparatus, product, or process disclosed, or represents that its use would not infringe privately owned rights. Reference herein to any specific commercial product, process, or service by trade name, trademark, manufacturer, or otherwise, does not necessarily constitute or imply its endorsement, recommendation, or favoring by the United States Government or any agency thereof. The views and opinions of authors expressed herein do not necessarily state or reflect those of the United States Government or any agency thereof. 
GA-A16027

\title{
HTGR-GT PRIMARY COOLANT TRANSIENT RESULTING FROM POSTULATED TURBINE DEBLADING
}

\author{
by \\ G. J. CADWALLADER and R. K. DEREMER
}

This is a preprint of a paper to be presented at the 26th annual ASME International Gas Turbine Conference, Houston, Texas, March 1981.

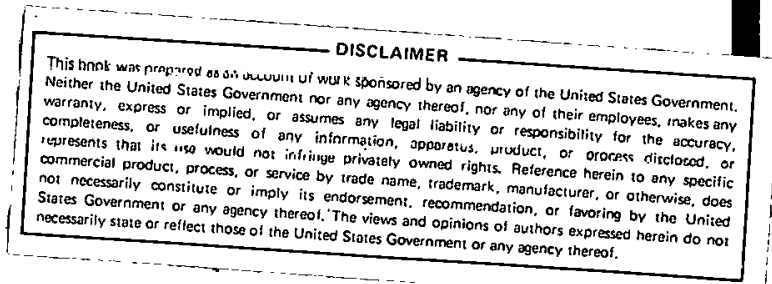

Work supported by

Department of Energy

Contract DE-AT03-76SF70046

\section{GENERAL ATOMIC PROJECT 6800 NOVEMBER 1980}

\section{GENERAL ATOMIC COMPANY}




\title{
HTGR-GT PRIMARY COOLANT TRANSIENT RESULTING FROM POSTULATED TURBINE DEBLADING
}

\author{
by \\ G. J. Cadwa1lader ${ }^{1}$ and R. K. Deremer ${ }^{2}$ \\ General Atomic Company \\ P.0. Box 81608 \\ San Diego, California 92138
}

\section{ABSTRACT}

The turbomachine is located within the primary coolant system of a nuclear closed cycle gas turbine plant (HTGR-GT). The deblading of the turbine can cause a rapid pressure equilibration transient that generates significant loads on other components in the system. Prediction of and design for this transient are important aspects of assuring the safety of the HTGRGT. This paper describes the adaptation and use of the RATSAM program to analyze the rapid fluid transient throughout the primary coolant system during a spectrum of turbine deblading events. Included are discussions of (1) specific modifications and improvements to the basic RATSAM program, which is also briefly described; (2) typical results showing the expansion wave moving upstream from the debladed turbine through the primary coolant system; and (3) the effect on the transient results of different plenum volumes, flow resistances, times to deblade, and geometries that can choke the flow.

1 Sr. Engineer

2 Staff Englneer; Member ASME 


\section{INTRODUCT ION}

In the direct cycle high-temperature gas-cooled reactor (HTGR-GT) concept, the helfum turbomachines are positioned within the primary coolant system in horizontal cavities located below the core, as shown in Fig. 1. Because of this integral arrangement accidents associated with the turbomachines, such as deblading and shaft fallure, can produce significant pressure, temperature, and flow transients throughout the primary coolant system.

The Inherent and passive safety characteristics of the HTGR mitigate many of the consequences of such accidents. Nevertheless, for the more severe turbomachine failures that are postulated, it might be necessary to improve or reinforce designs which have evolved through the development of the steam cycle HTGR plant.

of particular concern is the ability to maintain a coolable core geometry after the accident. To guarantee this conling it is necessary to show that romponents in the flow patli cain survive, with a high degree of assurance, the rapid pressure, temperature, and flow transients and loads which can accompany severc turbomachine fallures.

Althugh recent studies have shown that the occurrence frequency of turbomachine failures is quite low, it is desirable to show that these postulated events do not lead to significant release of radioactivity to the environment. The RATSAM program (1), which was developed originally for the steam cycle HTGR, has been selected to cvaluate the transient response of the primary coolant system to turbomachine fallures and provide the data required by the designers to ensure the safety of the HTGR-GT plant. A description of this program, as it was adapted to the direct cycle concept, is presented in the next section.

\section{ANALYTICAL METHODS}

Preliminary studies of the turbine debladiny event indicated that the entire primary coolant system would have to be included in the analytical model in order to achieve meaningful results. Accordingly, the RATSAM program was selected for this purpose.

The RATSAM computer program was originally developed by General Atomic Company to evaluate the transient thermal and fluid flow behavior of the primary coolant system of a large, steam cycle HTGR during postulated transients such as the design basis depressurization accident (DBDA). In response to an appropriate forcing function, the program calculates the time-dependent pressure, temperature, and flow throughout the primary coolant system, taking into account the dynamic behavior of the helium circulators (for the steam cycle planc) and assuciated valves, the automatic action of the plant protiption systems. and the heat tianfer between coolant, core, and heat exchangers.

The RATSAM program user must provide a geometric description of the primary coolant system, protection system setpoints, and an approprlate set of inftial conditions. The program then applies the thermodynamic conservation equations, the equation of state, and other relationships to each userdefined control volume and fluid flow path to compute the transient quantities of interest.

Adaptation of the program to the HTGR-GT concept required a number of revistons to the steam cycle version of the program. The dynamic circulator model for the steam cycle plant was replaced by a dynamic turbomachine mode1. Control and bypass valve flow paths were added for the HTGR-GT version as well as unique control and protection features. Node-ton-node heat transfer was also added to permit simulation of the Hitik-i recuperaluss. 


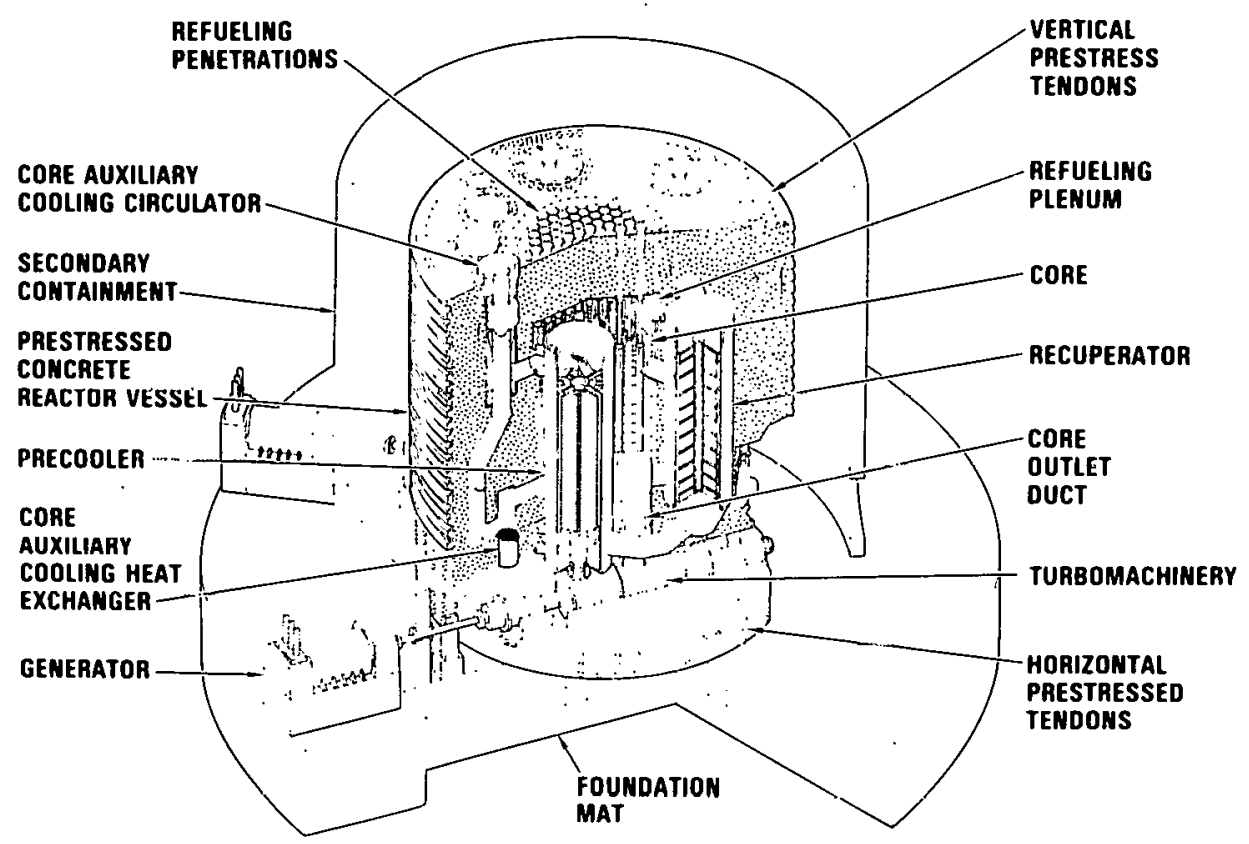

F1g.1 Reactor turbine system arrangement

The dynamic turbomachine and bypass valve models incorporated into the RATSAM program were taken directly from the REALY2 program (2). The turbowachine model uses tables of turbinc and compressor characteristics to simulate dynamic behavior. The bypass valve flow path model accounts for choked flow at the valve and frictinn efferts in the dicts upstream and downstream of the valves.

Unique HTGR-GT control functions which have been lincorporated into the RATSAM program include (1) a turhnmachtine overspeed trip which triggers a reactor trip and causes bypass valves to open, and (2) a signal to trip the turbine when out of phase with the (assumed) grid.

\section{PROGRAM VERIFICATION}

In the absence of experimental data for an H'ike, the validity of the program must be establistied by comparing its resules with experimental data obtained for similar thermodynamic systems, or with results gencrated by an independently validated program. For rapid transients, two sources have been used to verify the RATSAM program. The first source is the depressurization experiment associated with the Calder Hall Stage 1 reactor model and the second is a comparison of RATSAM results with those generated for an HHT turbine deblading accident by E1dg. Institut Fur Reaktorforschung (EIR) using the PLAYGAS program (3).

A simplified schematic of the Calder Hall Stage 1 reactor model is shown in Fig. 2. The model is $1 / 18$ th of the full-size reactor and consists of a pressure vessel connected to four circuits, each of which contains a chamber to represent the heat exchangers. Circulator impellers were simulated by orifice plates located in the ducts on the output side of the 1mpeller casings. Model design parameters and experimental results were reported by Moore and Walford (4). Based on these parameters,

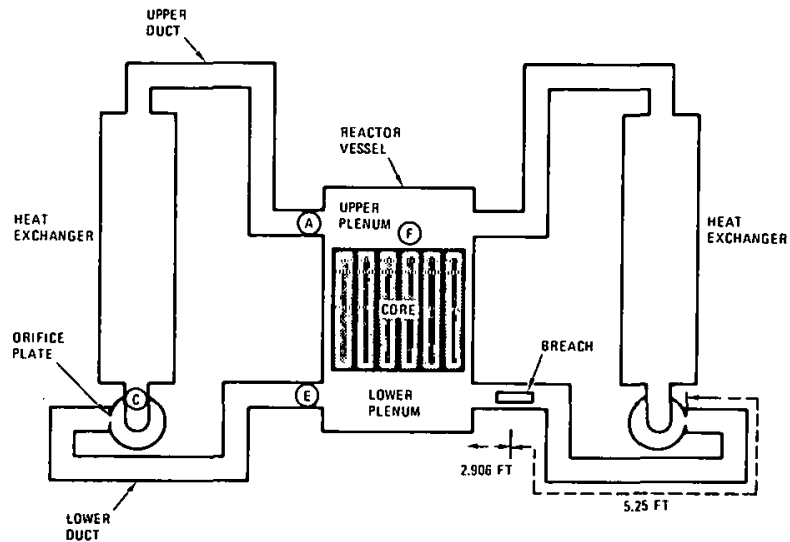

F1g.2 Calder Hall Stage 1 reactor model

the node-flowpath model shown in Fig. 3 was developed for the RATSAM program. The duct containing the breach is simulated by two leak flow paths, one connected to the lower core plenum and the other to a heat exchanger chamber. It was assumed that no heat transfer took place between the walls and gas during the time period of interest.

Results of the RATSAM program are compared with experimental data for two different gases in Figs. 4 through 7. Figures 4 and 5 are based on experiments performed with $\mathrm{CO}_{2}$, while F1gs, 6 and 7 reflect experimental data using air. The RATSAM predictions of pressure histories throughout the reactor model system appear to be in excellent agreement with the test data. As shown In Figs. 5 and 7 , it is slightly more difficult to predicr time-dependent 


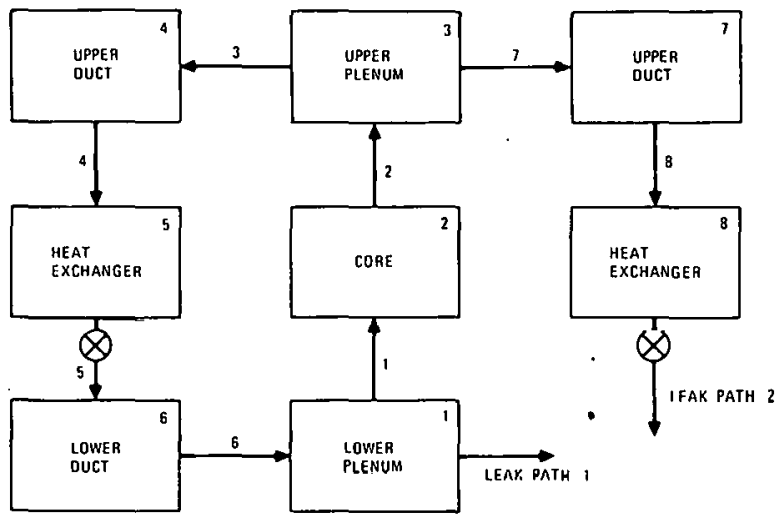

Fig.3 RATSAM representation of the Calder Hall Stage 1 reactor model

6
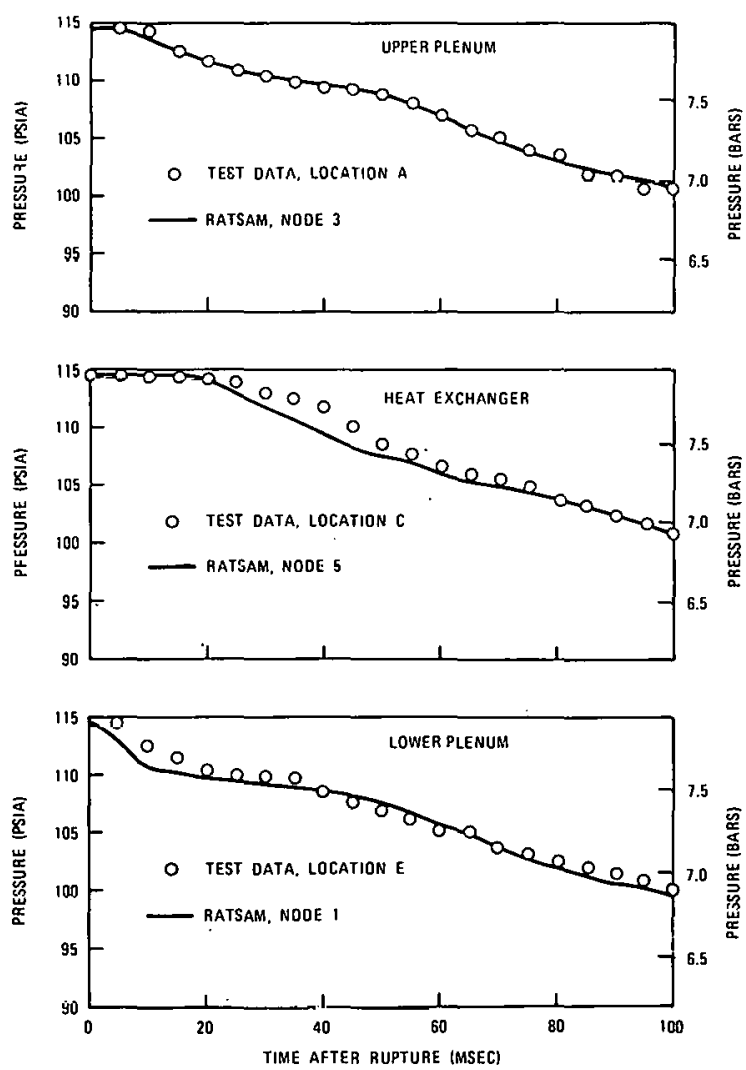

F1g.4 Comparison of RATSAM results for pressure history with Calder Hall. Stage 1 model experimental data for $\mathrm{CO}_{2}$
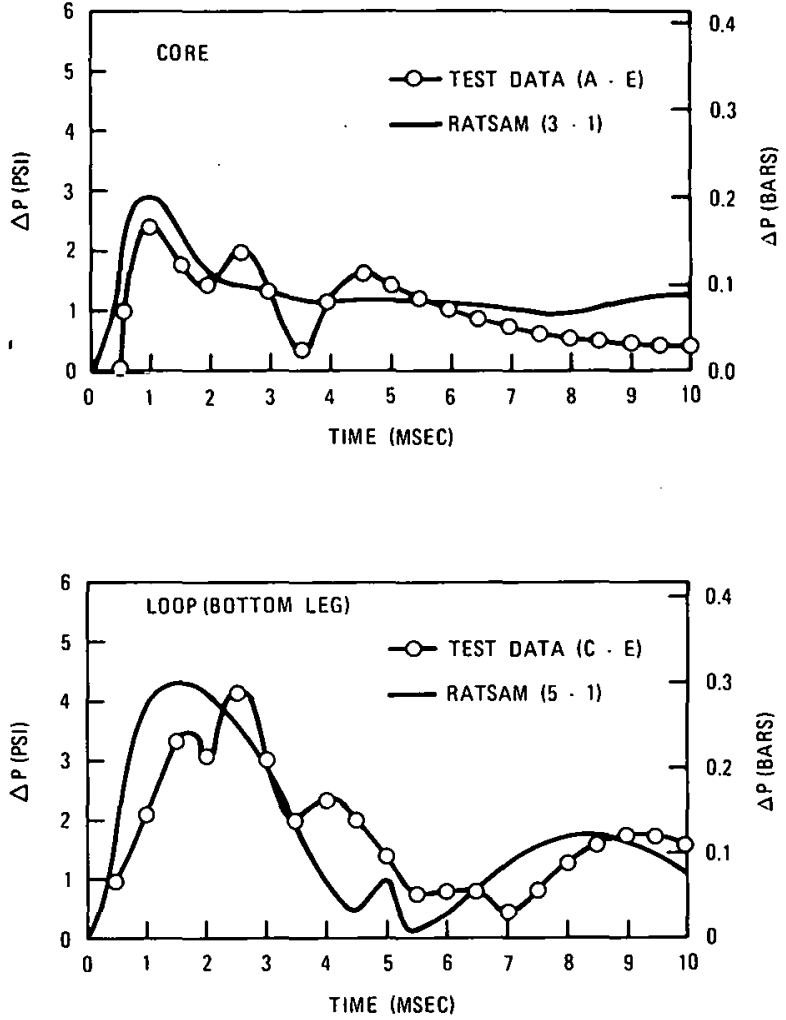

F1g.5 Comparison of RATSAM results for $\triangle \mathrm{P}$ history with Calder Hall Stage 1 model experimental data for $\mathrm{CO}^{\circ}$

pressure differentials. However, the agreement shown in peak values and trends between the RATSAM predictions and the experimental results is very good.

The difficulty in predicting the fluctuation in these pressure differentials results from several

factors. First, small errors in the absolute pressure measurements can lead to large errors in the differential pressures. In addition, the pressures predicted by the RATSAM program represent averages taken over entire subvolumes (or nodes), while those recorded during the experiubent by pressurc instruments represent very local values. Also, due to the lack of detailed design information there is some imprecision in simulating flow resistances representing flow ducts, orffices, and rupture paths. Additional nodes and flow paths in the RATSAM model would also tend to Improve the comparison; however, the avallability of data did not warrall such improvements.

The comparison of RATSAM predictions with those of the PLAYGAS program for a turbine deblading event was a joint effort of EIR and General Atomic Company and involved several iterations. These 1 terations resulted from several clarifications of model simulation and physical data interpretalion. The HHT turbine deblading accident, as simulated by the PLAYGAS program, was reported in Reference 5 . The RATSAM modol of this "henrhmark problẹ" is shown in 


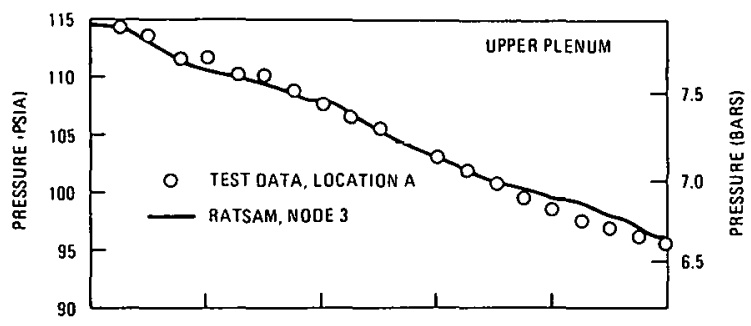

Fig. 8. For this accident, turbine deblading is simulated by a nozzle with a linearly changing area. A comparison between predicted parameters of interest is shown in Figs. 9 and 10 . As Indicated, the agreement between the RATSAM and PLAYGAS predictions is very good and one can present a strong case for stating that the two programs verify one another.
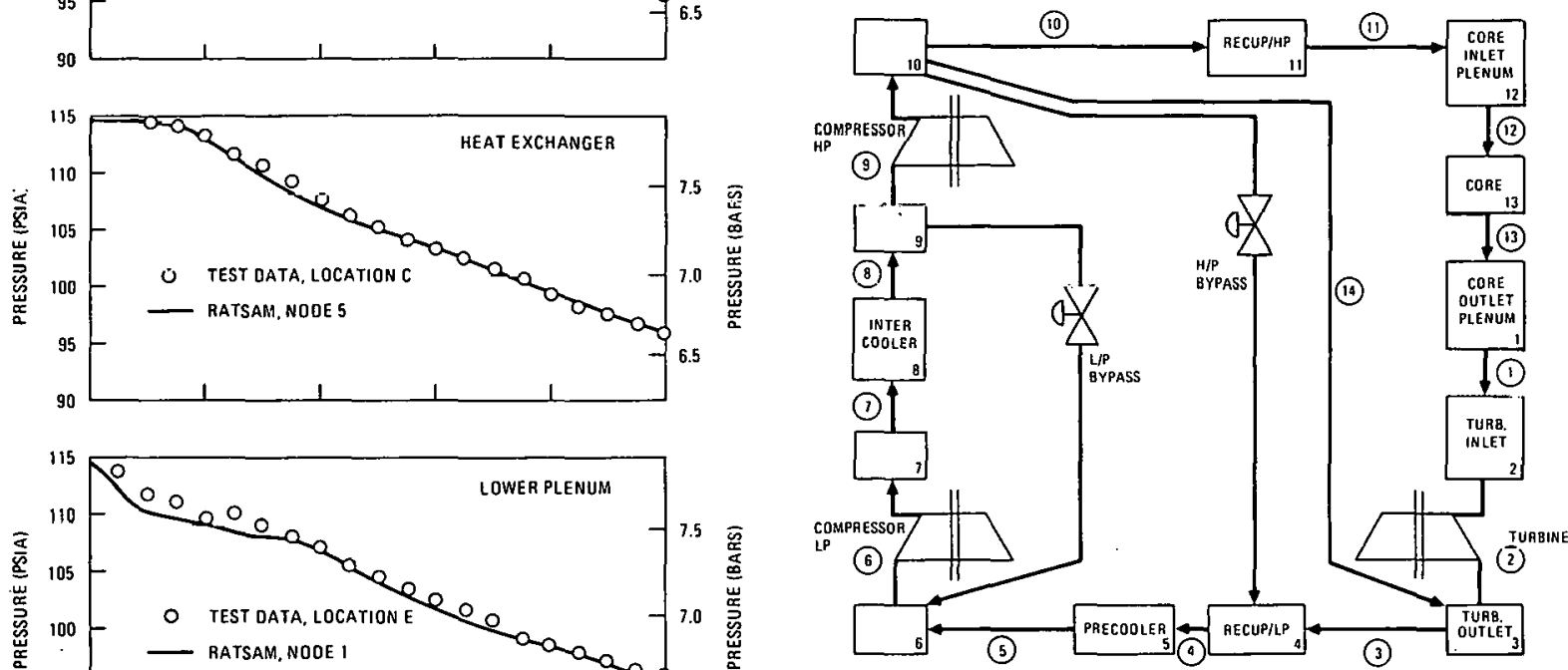

Fig.8 RATSAM model of HHT demonstration plant for benchmark comparison with PLAYGAS

\section{SIMULATION OF TURBINE DEBLADING}

The geometric model of nodes and flow paths created for an HTGR-GT with two turbomachines is shown in $\mathrm{Fig.} 11$.

For the purpose of analyzing the turbine de-
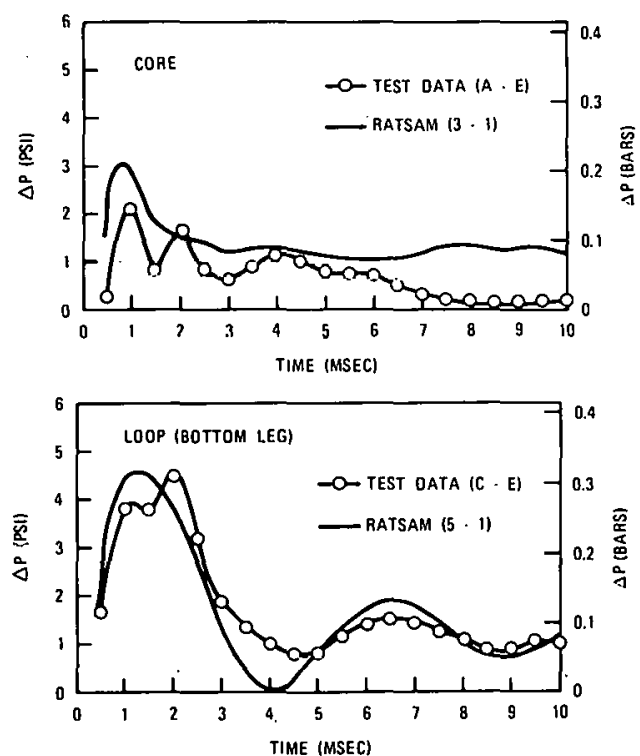

Eig.7 Comparison of RATSAM results for $\triangle \mathrm{P}$ history with Calder Hall. Stage 1 model experimental data for afr blading event in an path has been represented as a large flow resistance that decreases as the turbine deblades. This representation is compatible with the modeling of total deblading events as well as the more 11 kely partlal deblading events. The final resistance thus may represent inlet and exit losses only, or fit may include guide blades or turbine stages that remain after a partial deblading.

Turbine resistance is assumed to decrease linearly with time as the turbine deblades. This is based on the assumptions of (1) sequential stageby-stage removal of blades over time; (2) a litiear pressure drop from stage to stage; and (3) pressure drop from stage-to-stage proportional to flow resistance only, i.e., the influence of mass flow and density are neglected.

The first assumption is based on a model where debris from the first turbine stage is carried dowtstream into the second, causing it to deblade, and so forth, each stage in turn. The second assumption can be shown to be a falrly good approximation at mass flows close to the nominal design point for multi-stage turbines, as 11lustrated in Fig. 9 of Bammert and Zehner ( 6 ). The third assumption would be a good approximation if the mass flow did not increase, but produces resistances that are higher than they would be if the Increased flow was taken Into account: All three assumptions taken togetlier 


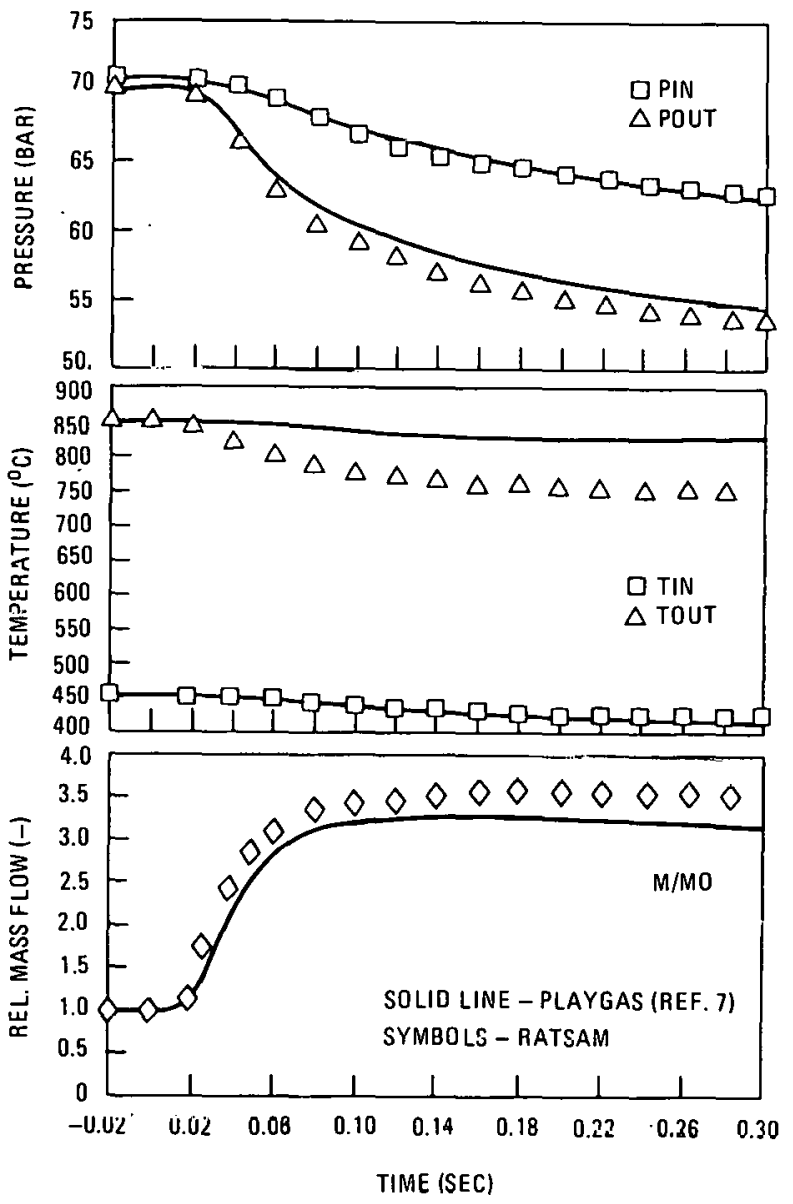

Fig.9 Comparisull of RATSAM recults for core parameters with PLAYGAS results

result in a linear decrease in flow resistance over the deblading time.

simulating the deblading turbine as a diminishIng resistance to flow allows the fluld in the turbine to accelerate accordingly, taking into account the inertia of the fluid. This is believed to be more realistic than simulating the turbine as an orifice that opens over a period of tlue to allow more and more flow, because the use of quasi-steady nozzle equations to determine the transient flow consistent with the new area and prevalling upstream pressure produces the equivalent of instantaneous flow acceleration and can result in an earlier and more gradual pressure equilibration, particularly over longer deblading rimes, as shown in F1g. 12. For very short deblading times, a diminishing resistance produces a slightly less severe transient than an opening orifice. The RATSAM model allows the fluld to accelerate thirough the turbine according to the momentum equation until it reaches the flow rate corresponding to that through a nozzle or orifice with an appropriate area, such as that at the entrance to the bladed portion of the turbine, whereupon the flow is assumed to become choked and the flow rate is determined as for isentropic flow through an orifice.

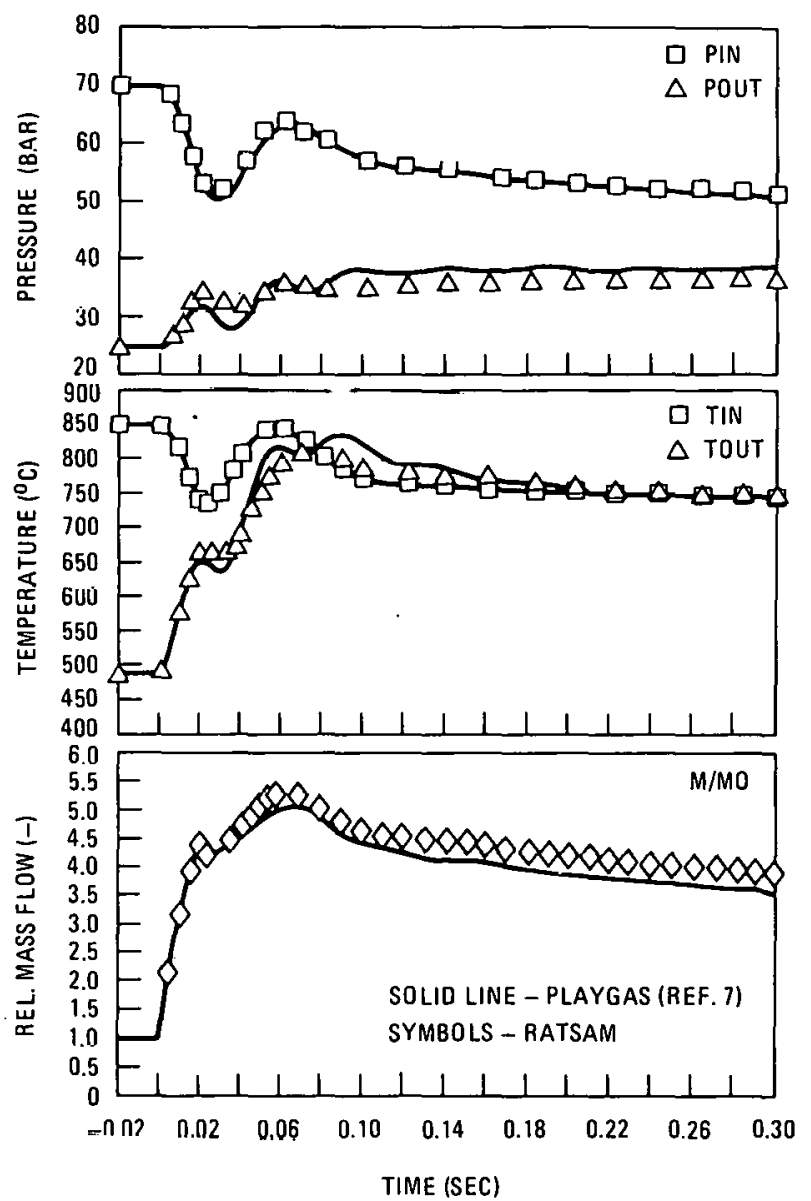

Fig.10 Comparison of KATSAM results for turbine parameters with PLAYGAS results

During a rapld pressure equilibration event, the low pressure region downstream of the turbine wlll pressurizc rapldly, and weak compression shocks may be expected. However, the flow path geometry in the HTGR-GT is so Irregular and tortuous that any shocks are expected to be attenuated quickly. Therefore, shocks downstream of the turbine are neglected in the RATSAM analysis.

\section{RESULTS OF INTEREST}

A typical turbine deblading event that has been analyzed is one where the turbine is assumed to deblade at the rate of one stage per revolution. Thus a nine-stage curbine rotating at $3600 \mathrm{rpm}$ unuld totally deblade in 0.150 seconds.

Detalls of the pressure transient in the reactor core and the falled turbomachine loop are shown In Figs. 13 through 15. Figure 13 showg that the turbine inlet plenum depressurizes slowly at first, then more rapidiy as the fluld accelerates through the deblading turbine, until the fluid reaches sonic velocity and chokes at the turbine inlet, as shown in Fig. 16. The fluid in the duct fooding the turbine has been accelerating as well, 


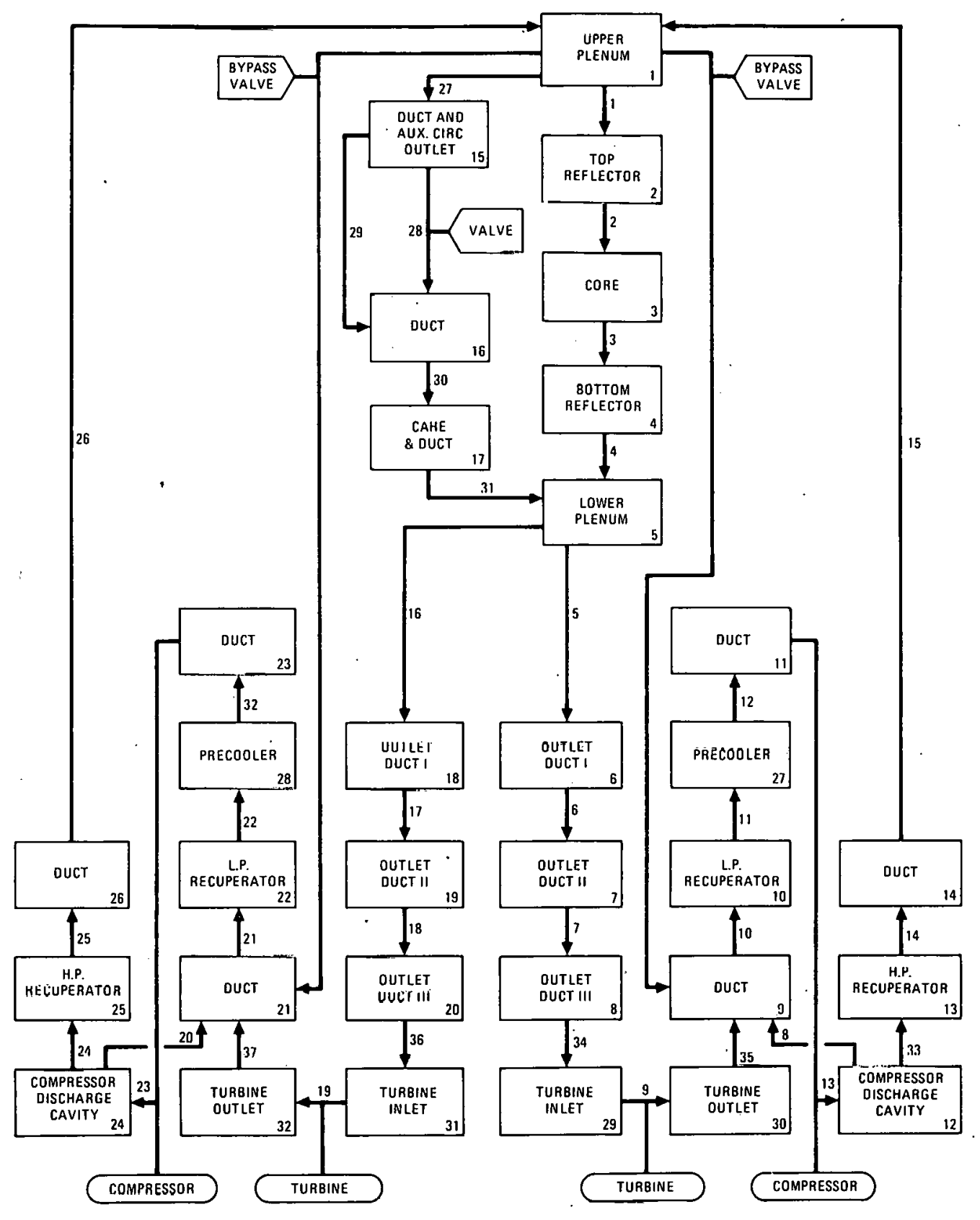

Fig.11 RATSAM model of two-loop 800 MW(e) optimized HTGR-GT 


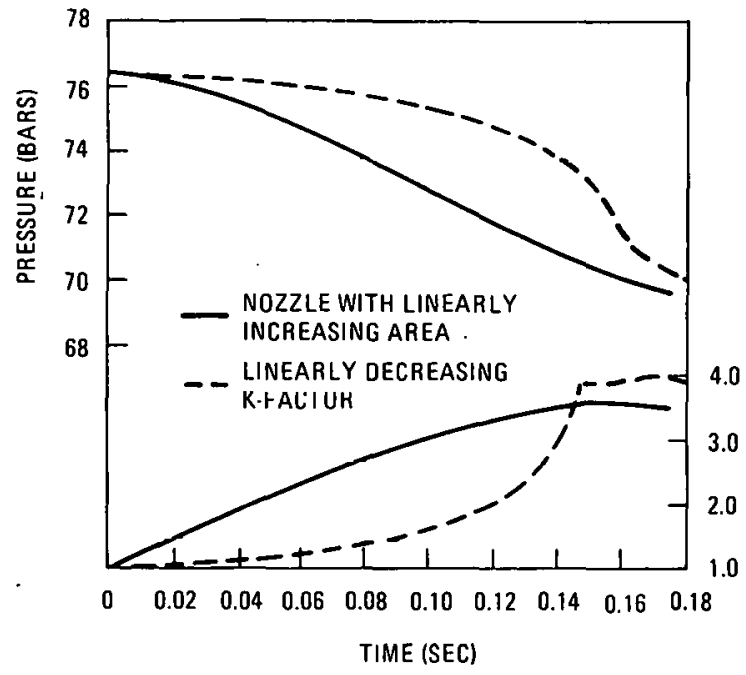

Fig.12 HTGR-GT core outlet plenum pressure and relative mass flow during turbine deblading for two different turbine deblading simulation models

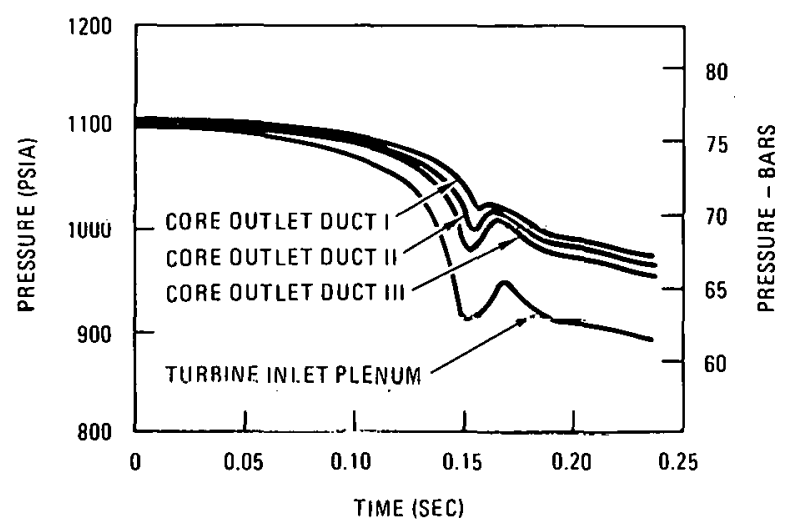

Fig.13 HTGR-GT core outlet duct and turbine inlet pressures during turbine deblading

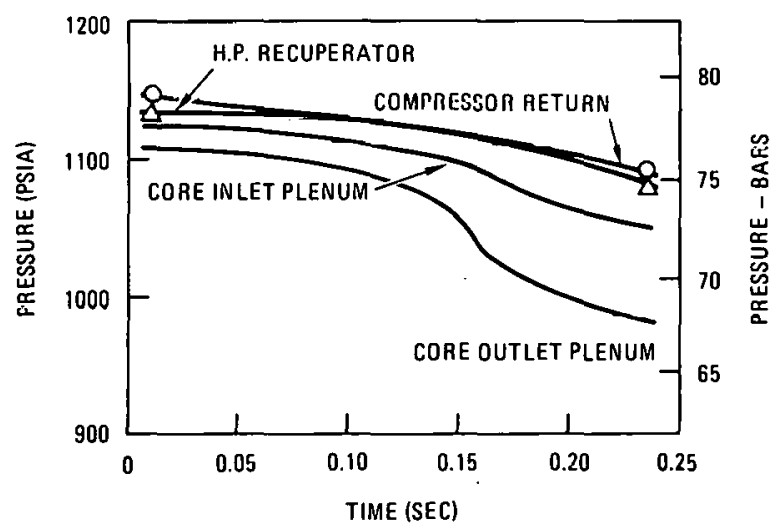

FIg. 14 Selected HTGR-GT inigh pressure region pressures during turbine deblading

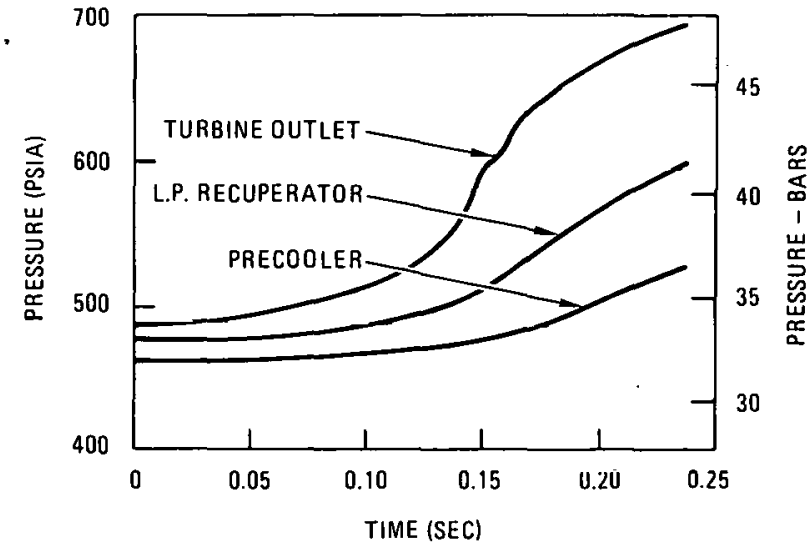

Fig.15 Selected HTGR-GT low pressure region pressures during turbine deblading

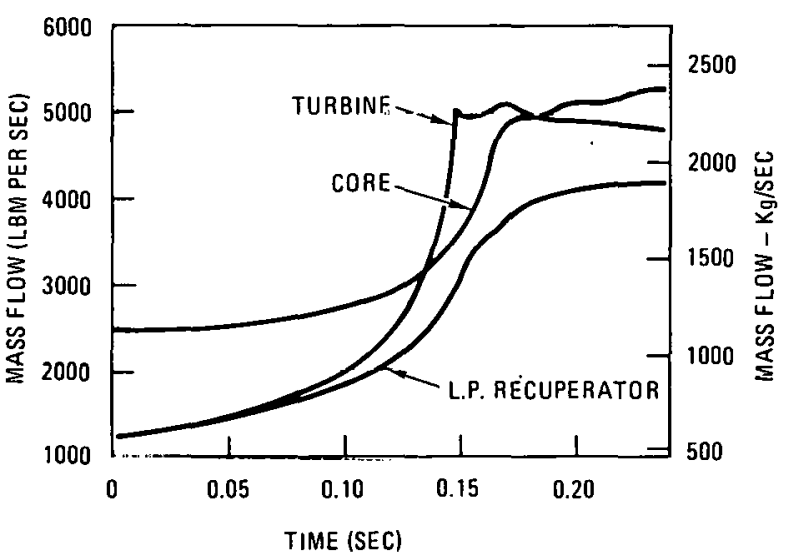

F1g.16 Selected HTGR-GT flow rates during turbine deblading

but lags that through the debladed turbine. Thus expansion waves are seen to travel up the duct to the core outlet and inlet plena. As the choking occurs, the duct fluld rushes into the turbine inlet plenum more rapidly lian it leaves, causing a partial repressurization. The response in the duct is also a slight increase in pressure before the depressurization continues. The purpose of dividing the duct into small nodes is to observe the pressure transient in some detall in the duct. The smaller the nodes, the more detall that would be avallable. However, the number of nodes assumed for the duct does not appear to have a significant impact on the depressurization rate of the core outlet plenum. The core outlet and inlet plenum pressures also drop, and can be seen in Fig. 14 to lag the pressure transient in the duct. Figure 15 shows the rapid pressurization of the low pressure portion of the falled loop.

The turbine inlet duct pressure in the Intact turbomachine loop follows the core outlet plenum pressure. Flow to that turbine decreases; flow from that compressor back to the depressurizing core inlet plenum increases. 
It is significant that the failed loop pressures drop most rapidly at the end of the deblading time, when the final stages are removed from the turbine path. This agrees with observed turbine debladings which were accompanied by a "blast" of debris at the end of the deblading. This blast contrasts with results based on simulating the deblading turbine as a nozzle or orifice opening linearly to some final flow area. In that case, the flows are higher through the turbine sooner, and the upstream reglons depressurlze sooner but more gradually, as shown in Fig. 12.

The rapidity of the pressure transient in the core outlet plenum is one major safety concern, as it affects the design of thermal barrier coverplates. The effect on core outlet plenum depressuriation rate of various parameters related to the core design and deblading assumptions has been eva1uated. Geometry and design variables include the core outlet plenum volume and the pressure drop or flow resistance through the core. With a larger outlet plenum volume, and fluid mass, the same flow rate removes a smaller percentage of mass per unit time, resulting in a less severe depressurization transient in the outlet plenum. A smaller core differential pressure, allowing easler communication between the inlet and outlet plena, effectively increases the outlet plenum volume and also decreases the rate of depressurization.

Deblading assumptions that have been varied include the time over which the turbine loses its resistance, the flow resistance remaining at the end of the deblading, and whether the turbine flow path geometry chokes the flow. The time to deblade has been varied from one revolution per turbine stage ( 0.150 seconds) to one revolution ( 0.017 seconds) total. The outlet plenum depressurizes more capidly when the turbine is assumed to deblade faster, since the mass flow increases much more rapidly as the flow resistance is decreased yulckly. The flow rosistance remalning at the end of the deblading has represented just inlet and exit losses on the one hand, or one or more remalning stages of gulde vanes or. rotor blades. The resistance equivalent to one stage of inlet guide vanes was seen to reduce the core outlet plenum depressurization rate by onethird. If the deblading is assumed to leave a flow geometry through the turbine of sufficiently small cross-sectional area, the flow can become choked, so that 1t will accelerate no further. The flow rate is proportional to the area, so the final choked flow rate depends on the area. The smaller the area and flow, the more slowly the core outlet plenum depressurizes. The turbine inlet annulus in the plant analyzed here has an area such that when it is assumed to remain intact, the resulting core outlet plenum depressurization rate is one-third lower than the case where the geometry is assumed not to cause choking. If the first stage of guide vanes is assumed to remain, causing even more of an area constriction, the rate of core outlet plenum depressurization is reduced by one-third again. The combination of smaller flow area and increased flow resistance through a stage of gulde vanes actually reduced the outlet plenum depressurization rate by two-th1rds.

\section{SUMMARY AND CONCLUSIONS}

To guarantee a coolable core geometry after a turbine deblading event in an HTGR-GT it is necessary to show that components in the primary coolant flow path can survive the resulcant rapld jiessure, temperature, and flow transients and loads. The RATSAM program is being used to evaluate the transient thermal and fluld flow behavior of the primary coolant system following a turbine deblading event. The validity of the program for rapid transients has been established by compartig its results with experimental data obtained using the Calder Hall reactor model, and by comparing its results with results generated for an HHT turbine deblading accident using the PLAYGAS program.

The deblading turbine path has been represented as an initially large linearly decreasing flow resistance, which allows the fluid in the system to accelerate taking into account its inertia. As the pressures equilibrate an expansion wave moves upstream from the curbine.

Design parameters and deblading assumptions have been varied to study the sensitivities of the transient results. Larger upstream volumes, longer deblading times, and larger remaining flow resistance in the turbine path all contribute to mitigating the rate of pressure equilibration.

The design adequacy of components critical to safely cooling the reactor core has been evaluated using RATSAM program transient results for particular HTGR-GT geometric destgns. In general, existing component designs either have been found to be adequate or required only minor modifications.

\section{ACKNOWLEDGMENTS}

The authors wish to thank the management of General Atomic Company for permission to publish this paper. Work on the HTGR-GT has been supported by the U.S. Department of Energy under contract DEAT03-76SF70046.

\section{REFERENCES}

1 Deremer, R.K., and Shih,"T., "RATSAM: A Computer Program to Analyze the Transient Behavior of the HTGR Primary Coolant System During Accidents," General Atomic. Report GA-A13705, May 1977.

2 Croft, M.Z., "REALY2: The GT-HTGR Transient Performance Analysi's Program," General Atom1c ReporL GA-A13880, March 31, 1976.

3 Dupont, J.F., Cina, G., and Dang, M., "PLAYGAS, A Computer Code for the Transient Analysis of Nuclear Gas Turbine Power Plants," EIR-Bericht Nr. 284, July 1975.

4 Moore, J.C., and Walford, F..T., "Baslc Translent Flow Studies in Stage 1 Reactor Models," Journal of British Nucleat Energy Soclety Vol. 3, No. 3, July 1964, Pp. 174-185.

5 Dang, M., Dupont, J.-F., Jacquemoud, P., and Mylonas, R., "Pressure Translents Analysis of a High-Temperature Gas-Cooled Reactor with D1rect HelIum Turbine Cycle," IAEA Specialtsts' Meeting on "Gas-Cooled Reactor Safety and Licensing Aspects," September 1-3, 1980, Lausanne, Sw1tzerland.

6 Bammert, K., and Zehner, P., "Measurements of the Four-Quadrant Characteristics on a MultiStage Turbine," ASME Paper No. 79-GT-107, 1979. 


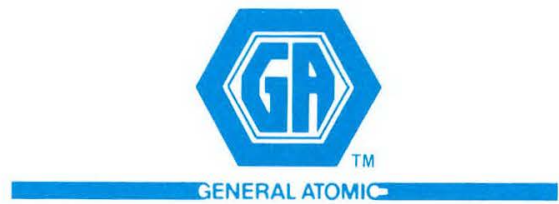

GENERAL ATOMIC COMPANY P. O. BOX 81608

SAN DIEGO, CALIFORNIA 92138 